\title{
Colon cancer cells treated with 5-fluorouracil exhibit changes in polylactosamine-type $\mathrm{N}$-glycans
}

\author{
LIPING GAO $^{1 *}$, LI SHEN ${ }^{1,2^{*}}$, MEIYUN YU $^{1}$, JIANLONG NI $^{1}$, XIAOXIA DONG ${ }^{2}$, \\ YINGHUI ZHOU ${ }^{1}$ and SHILIANG WU ${ }^{1}$ \\ ${ }^{1}$ Department of Biochemistry and Molecular Biology, Soochow University, Suzhou, Jiangsu 215123; \\ ${ }^{2}$ Department of Clinical Oncology, Taihe Hospital, Hubei University of Medicine, Shiyan, Hubei 442000, P.R. China
}

Received June 20, 2013; Accepted February 3, 2014

DOI: $10.3892 / \mathrm{mmr} .2014 .2008$

\begin{abstract}
Fluorouracil (5-FU) is the major chemotherapeutic agent for the treatment of colorectal carcinoma, which were found to have $\mathrm{N}$-glycans containing polylactosamine on the cancer cell surface. Alterations in the expression and structure of polylactosamine glycans are associated with cellular differentiation and oncogenesis. However, little is known with regard to the correlation between the levels of polylactosamine expressed in colon cancer cells and the anticancer effect of 5-FU. In the present study, SW620 cells were treated with the half maximal inhibitory concentration $\left(\mathrm{IC}_{50}\right.$; determined by MTT-assay) of 5-FU. Hoechst 33258 staining and flow cytometric analysis indicated that 5-FU administration resulted in apoptosis in SW620 cells. An increased percentage of cells in $\mathrm{S}$ phase was also observed among the SW620 cells treated with 5-FU. Under the same experimental conditions, a decrease in the 5-FU-induced inhibition of polylactosamine glycans was recorded. However, an increase in the activity of alkaline phosphatase was also observed. Furthermore, pretreatment of the SW620 cells with 5-FU inhibited the expression of $\beta 1,3-\mathrm{N}$-acetylglucosaminyltran sferase-8 ( $\beta 3 \mathrm{Gn}-\mathrm{T} 8)$ and cluster of differentiation (CD)147 in a time-dependent manner. Overall, changes in glycosylation were associated with the anticancer effect of 5-FU in the colon cancer cells. In conclusion, polylactosamine may be a useful target for the identification of substances with anticancer activity.
\end{abstract}

Correspondence to: Dr Shiliang $\mathrm{Wu}$ or Dr Yinghui Zhou, Department of Biochemistry and Molecular Biology, Soochow University, No.1 Shizi Street, Suzhou, Jiangsu 215123, P.R. China

E-mail: wushiliang@suda.edu.cn

E-mail: zhouyinghui@hotmail.com

*Contributed equally

Key words: 5-fluorouracil, colon cancer, polylactosamine, N-glycans

\section{Introduction}

5-Fluorouracil (5-FU) remains a widely used anticancer drug. An improvement in the response and survival rates in breast, head and neck cancer has been observed following administration of 5-FU and other chemotherapeutical agents. However, the largest impact has been observed in colorectal cancer. As a pyrimidine analogue, 5-FU interferes with nucleoside metabolism and is incorporated into RNA and DNA, finally leading to cell cycle arrest and apoptosis. There are numerous identified and potential modulators that contribute to the 5-FU response in cancer cells. For example, celecoxib combined with 5-FU has been shown to enhance tumor cell apoptosis and anticancer efficacy in a subcutaneous implantation tumor model of colon cancer (1). Also, the inhibition of O-glycosylation by benzyl- $\alpha-\mathrm{N}$-acetylgalactosamine resulted in significant antiproliferative activity of 5-FU against pancreatic cancer cells (2). In addition, 5-FU has the potency to change cellular glycosylation in various cell types (3).

Colon cancer cells frequently contain glycans at different levels or with fundamentally different structures than those observed on normal cells. Recently, Yang et al confirmed that colon cancer was associated with antigenic and structural changes in mucin-type O-glycans (4). In addition, Barrow et al identified that in human colon cancer cells, the suppresion of core 1 galactose (Gal)-transferase is linked to a decrease in the Thomsen-Friedenreich (TF) and a corresponding increase in $O$-[2-(acetylamino)-2-deoxy- $\alpha$-D-galactopyranosyl]-L-se rine (Tn), sialyl-Tn and Core 3 glycans (5). In another study, core fucosylated high mannose $\mathrm{N}$-glycans were detected in colorectal cancer tissues using hydrophilic interaction liquid chromatography with matrix-assisted laser desorption/ionization time-of-flight mass spectrometry (6). Furthermore, Hahne et al (7) analyzed the N-glycosylation profiles of two colon carcinoma cell lines, SW480 (primary tumor) and SW620 (metastatic tumor). There was a significant downregulation of high-mannose glycans in the metastatic cells. Therefore, it is necessary to identify changes in glycans and to investigate the consequences of blocking or modifying glycosylation in colon cancer cells following 5-FU treatment. However, little is known with regard to glycan changes following 5-FU treatment during colon cancer progression. 
The glycosylation of polylactosamine uses repeating Gal $\beta 1-4$-glucosyl (Glc)- $N$-acetyl-(Ac)- $\beta 1-3$ disaccharide units that are preferentially joined to $\beta 1-6 \mathrm{GlcNAc}-$ linked antennae that are connected to the trimannosyl core of the complex-type $\mathrm{N}$-linked oligosaccharides (8). It has been reported that highly metastatic colon cancer cells synthesize more $\mathrm{N}$-glycans that contain polylactosamine than cells with low metastasis (9). In the present study, the human colon cancer cell line SW620 was pretreated with the half maximal inhibitory concentration $\left(\mathrm{IC}_{50}\right)$ of 5-FU for a short term. The apoptosis induction and cell cycle arrest that occurred within the first $48 \mathrm{~h}$ was examined. Under the same experimental conditions, the correlation between the levels of polylactosamine expressed in colon cancer cells and the anticancer effect of 5-FU were also investigated. Characterization of the glycan changes in response to short-term drug treatment in colorectal cancer cells will facilitate an improved understanding of the multiple mechanisms involved in drug response. Alteration in glycans result from disruptions in the expression levels of the glycosyltransferases. $\beta 3 \mathrm{Gn}-\mathrm{T} 8$ is an enzyme involved in the synthesis of polylactosamine on $\beta 1,6$-branched $\mathrm{N}$-glycans in colon cancer (10). Western blot analysis revealed that the expression of $33 \mathrm{Gn}-\mathrm{T} 8$ in the SW620 cells was markedly suppressed by 5 -FU (Fig. 5B). CD147 is a transmembrane glycoprotein containing polylactosamine-type glycans (11).

\section{Materials and methods}

Cell culture. The human colon cancer cell line SW620 was purchased from the Institute of Biochemistry and Cell Biology, Chinese Academy of Science (Shanghai, China), and cultured in RPMI-1640 medium (Invitrogen, Carlsbad, CA, USA) supplemented with $10 \%$ fetal bovine serum at $37^{\circ} \mathrm{C}$ under $5 \% \mathrm{CO}_{2}$.

Cell viability assays in vitro. SW620 cells were seeded onto a 96-well plate, with $5 \times 10^{3}$ cells in $180 \mu$ l culture medium being added to each well. Next, the cells were exposed to different concentrations of 5-FU $[0.01 \mathrm{x}$ peak plasma concentration (PPC), $0.1 \times$ PPC, $1 \times$ PPC and $10 \times$ PPC] for $48 \mathrm{~h}$. The cell viability was then determined for each time-point by adding $20 \mu 1$ MTT (5 mg/ml; Sigma-Aldrich, St. Louis, MO, USA) to each well and incubating the cells for $4 \mathrm{~h}$. The reaction was stopped by the addition of $150 \mu 1$ dimethyl sulfoxide, and the absorbance of the samples was then measured at $570 \mathrm{~nm}$ by means of an ELISA plate reader (BioTek Instruments, Inc., Winooski, VT, USA). The experiments were repeated at least three times. The concentration of 5-FU causing 50\% inhibition $\left(\mathrm{IC}_{50}\right)$ was determined by plotting the toxin concentrations versus percentages of inhibition (on a Probit scale), as calculated from the absorbance data.

Hoechst 33258 staining. The cells were seeded at a density of $5 \times 10^{4}$ cells $/ \mathrm{ml}$ in culture medium onto a $3.5-\mathrm{cm}$ sterile plate and incubated with $40 \mu \mathrm{g} / \mathrm{ml} 5-\mathrm{FU}$ for $48 \mathrm{~h}$. Subsequent to being washed twice with phosphate-buffered saline (PBS), the cells were fixed with $4 \%$ formaldehyde. The fixed cells were then incubated with $1 \mathrm{mg} / \mathrm{ml}$ nuclear fluorochrome Hoechst 33258 (Beyotime Biotechnology, Jiangsu, China) at room temperature for $10 \mathrm{~min}$ in the dark. The stained cells were observed under a fluorescence microscope.
Flow cytometry. Apoptosis was identified and quantified using flow cytometry with Annexin V-fluorescein isothiocyanate (FITC) and propidium iodide (PI) double-staining. In brief, $2 \times 10^{6}$ SW620 cells were treated with $40 \mu \mathrm{g} / \mathrm{ml}$ 5-FU for $48 \mathrm{~h}$, washed twice with cold PBS and then gently re-suspended in $195 \mu 1$ binding buffer. Thereafter, $5 \mu \mathrm{l}$ Annexin V-FITC $(20 \mu \mathrm{g} / \mathrm{ml})$ and $5 \mu \mathrm{l}$ PI $(20 \mu \mathrm{g} / \mathrm{ml}$; both Beyotime Biotechnology) were added. The cells were gently vortexed and incubated for $15 \mathrm{~min}$ while protected from light. Subsequent to adding $400 \mu \mathrm{l} \mathrm{X}$ binding buffer to each tube, the cells were analyzed using flow cytometry (Becton-Dickinson, Mountain View, CA, USA) within $1 \mathrm{~h}$.

Cell cycle analysis. The cells were treated with $40 \mu \mathrm{g} / \mathrm{ml} 5$-FU for $48 \mathrm{~h}$. The cultured cells were trypsinized and fixed with $70 \%$ ethanol at $4^{\circ} \mathrm{C}$ overnight prior to being stained with PI using freshly prepared staining solution. The distribution of cells in the different phases of the cell cycle was measured by flow cytometric analysis. The data were analyzed using CellQuest software (Becton-Dickinson).

Western blot analysis. Subsequent to 5-FU treatment ( $40 \mu \mathrm{g} / \mathrm{ml}$ ) for 24 or $48 \mathrm{~h}$, western blot analysis was conducted using standard methods. Briefly, equal amounts of protein (30 $\mu \mathrm{g} /$ lane) from total cell lysates were separated by $10 \%$ SDS-PAGE and transferred onto a polyvinylidene difluoride membrane. The membrane was blocked with $1 \%$ bovine serum albumin in Tris-buffered saline buffer [10 mM Tris and $150 \mathrm{mM} \mathrm{NaCl}$ (pH 7.9)] containing $0.05 \%$ Tween 20 , and the proteins were analyzed using specific antibodies as follows: Horseradish peroxidase-conjugated secondary antibodies and an enhanced chemiluminescence (ECL) kit were used for detection (both Beyotime Biotechnology). Rabbit anti-human $\beta 1,3-\mathrm{N}$-acetylglucosaminyltransferase- 8 ( $\beta 3 \mathrm{Gn}-\mathrm{T} 8$ ) polyclonal antibody was purified by our laboratory (12). Goat-anti-human cluster of differentiation 147 (CD147) antibody and mouse anti-human $\beta$-actin antibody were purchased from Santa Cruz Biotechnology, Inc. (Santa Cruz, CA, USA).

Flow cytometric analysis of cellular glycosylation. The cells were washed, collected from the plates and then centrifuged at $1,500 \mathrm{x} \mathrm{g}$ for $3 \mathrm{~min}$; the precipitate was resuspended in $100 \mu 1$ PBS. Next, the cells were incubated with $0.5 \mu \mathrm{g} / \mathrm{ml}$ biotin-conjugated Lycopersicon esculentum agglutinin lectin (LEL; Sigma-Aldrich) for $1 \mathrm{~h}$ at $37^{\circ} \mathrm{C}$. Cells were then washed and bound lectin was detected with phycoerythrin-conjugated streptavidin (Sigma) for $30 \mathrm{~min}$ at $37^{\circ} \mathrm{C}$. Cell samples were subjected to flow cytometry, with unstained cells serving as controls. Fluorescence histograms and mean fluorescence data were created and analyzed with CellQuest software (Becton-Dickinson).

Lectin blot. The cells were harvested and lyzed, proteins extracted from the cells were electrophoresed by $10 \%$ SDS-PAGE and polyvinylidene difluoride membranes were prepared as mentioned in the western blot analysis method. Following blocking with Carbo-Free Blocking Solution (Vector labs, Burlingame, CA, USA), the membranes were incubated with $2 \mu \mathrm{g} / \mathrm{ml}$ of various biotinylated lycopersicon esculentum agglutinin (tomato) lectins (LEL, TL; Vector labs) for $30 \mathrm{~min}$. The reactive bands were 


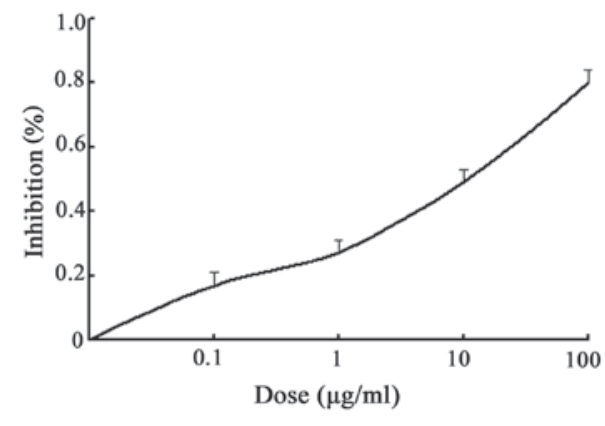

Figure 1. Effect of 5-FU on the growth of SW620 cells. Cells were treated for $48 \mathrm{~h}$ with different concentrations of 5-FU $(0.1,1,10$ and $100 \mu \mathrm{g} / \mathrm{ml})$. Cell growth was assessed by MTT assay. Values are presented as the mean \pm standard deviation. Experiments were performed in triplicate $(\mathrm{P}<0.05)$. FU, fluorouracil.

detected with a diluted horseradish peroxidase-conjugated streptavidin (Vector labs) and then visualized using an ECL system (GE Healthcare, Little Chalfont, UK).

Measurement of alkaline phosphatase (ALP) activity. For assessment of ALP, the ALP detection kit (Nanjing Jiancheng Bioengineering Institute, Nanjing, China) was used according to the manufacturer's instructions. The cells were seeded at a density of $1 \times 10^{4}$ cells $/ \mathrm{ml}$ and treated with $40 \mu \mathrm{g} / \mathrm{ml} 5-\mathrm{FU}$ prior to being assayed for ALP activity. Next, the homogenates were centrifuged at $12,000 \times \mathrm{g}$ for $30 \mathrm{~min}$ at $4^{\circ} \mathrm{C}$. The supernatants were subjected to quantification of protein with a Bradford assay and to an ALP activity assay using a detection kit. The enzymatic activities were expressed as U/g (protein).

Statistical analysis. Values are expressed as the mean \pm standard deviation. $\mathrm{P}<0.05$ was used to indicate a statistically significant difference. Statistical analyses were performed using SPSS 11.5 (SPSS, Inc., Chicago, IL, USA) and each experiment was repeated three times.

\section{Results}

Determination of the $I C_{50}$-value of 5-FU. In the present study, the effect of the conventional cytotoxic drug, 5-FU, was studied on the viability of SW620 cells. The PPC of 5-FU was $10 \mu \mathrm{g} / \mathrm{ml}$ (13), therefore, the cells were treated with 5-FU at concentrations of $0.11,1,10$ and $100 \mu \mathrm{g} / \mathrm{ml}$ for $48 \mathrm{~h}$. As shown in Fig. 1, 5-FU caused an evident reduction of cell viability, and the inhibitory effect was dose-dependent. The $\mathrm{IC}_{50}$-value of 5-FU on SW620 cells was calculated to be $13 \mu \mathrm{g} / \mathrm{ml}$. All the successive experiments were therefore performed on SW620 cells treated with $13 \mu \mathrm{g} / \mathrm{ml} 5$-FU.

Induction of apoptosis in SW620 cells by 5-FU treatment. To check whether 5-FU has a role in the regulation of apoptosis, the morphological changes of SW620 cells were examined using Hoechst 33258 staining. When the cells were stained with Hoechst 33258, live cells with uniformly light blue nuclei were observed under a fluorescence microscope, while apoptotic cells exhibited bright blue nuclei due to karyopyknosis and chromatin condensation, and necrotic cells can not be stained. As shown in Fig. 2A, the number of Hoechst 33258-positive apoptotic
A
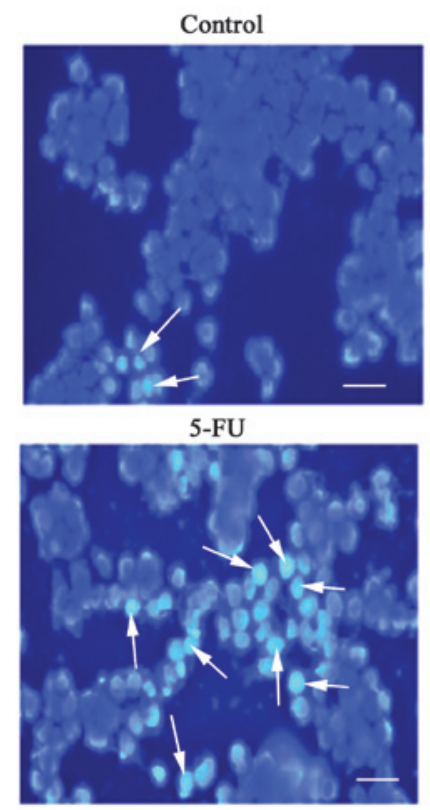

B
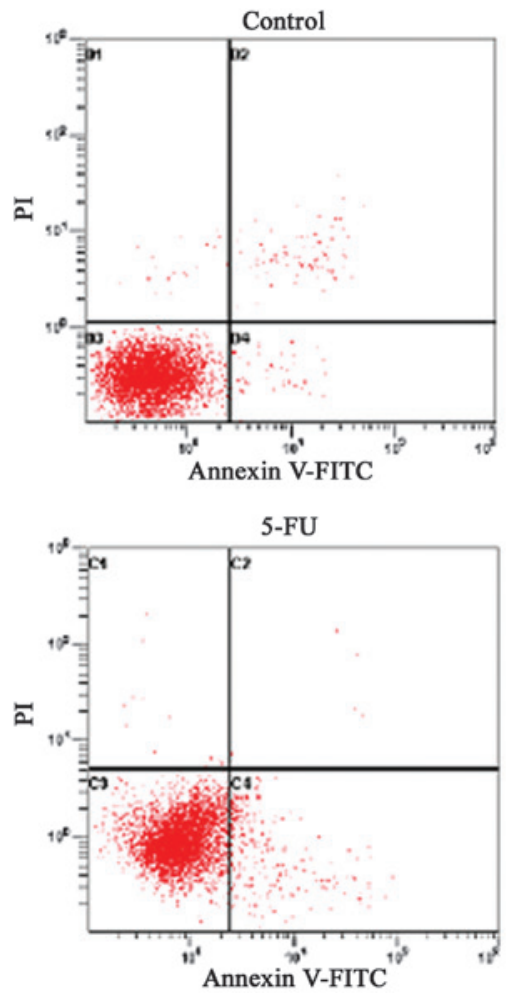

Figure 2. Effect of 5-FU on SW620 cell apoptosis. (A) Hoechst 33258 staining revealed normal nuclei in the control group, while cells treated with $13 \mu \mathrm{g} / \mathrm{ml}$ 5-FU exhibited condensed and fragmented nuclei, which are typical features of apoptosis. The arrows indicate apoptotic bodies. Original magnification, $\mathrm{x} 40$. Bar, $50 \mu \mathrm{m}$. (B) As revealed by flow cytometric analysis, Annexin V-FITC and PI double-staining indicated that a proportion of SW620 cells were apoptotic in following incubation with $13 \mu \mathrm{g} / \mathrm{ml} 5$-FU for $48 \mathrm{~h}$. The percentage of apoptotic cells was $9.29 \%$ compared with the control, in which only $1.05 \%$ of cells were apoptotic $(\mathrm{P}<0.05)$. FU, fluorouracil; FITC, fluorescein isothiocyanate; PI, propidium iodide.

cells following 5-FU treatment was increased compared with the control, demonstrating that the cells were apoptotic. Furthermore, the apoptosis triggered by 5-FU was confirmed by annexin V-FITC and PI double-staining and quantification by flow cytometry. As shown in Fig. 2B, incubation of SW620 cells 

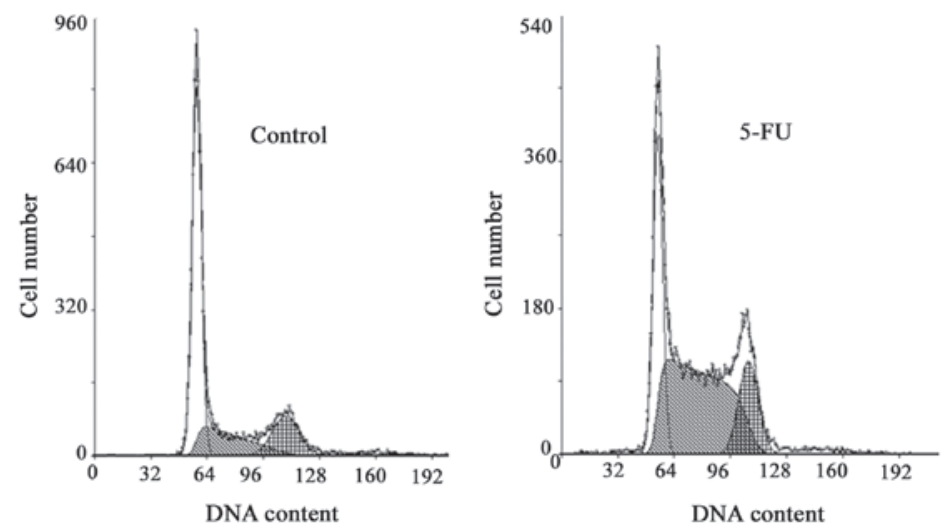

Figure 3. Effect of 5-FU on cell cycle arrest in S-phase. Untreated cancer cells (control); $\mathrm{G}_{0} / \mathrm{G}_{1}, 58.95 ; \mathrm{S}, 22.36$; and $\mathrm{G}_{2} / \mathrm{M}, 18.68 \%$; treated with $13 \mu \mathrm{g} / \mathrm{m} 15$-FU for 48 h. $\mathrm{G}_{0} / \mathrm{G}_{1}, 28.62 ; \mathrm{S}, 54.48$; and $\mathrm{G}_{2} / \mathrm{M}, 16.89 \%$. A representative result among three parallel analyses is shown. FU, fluorouracil.

A
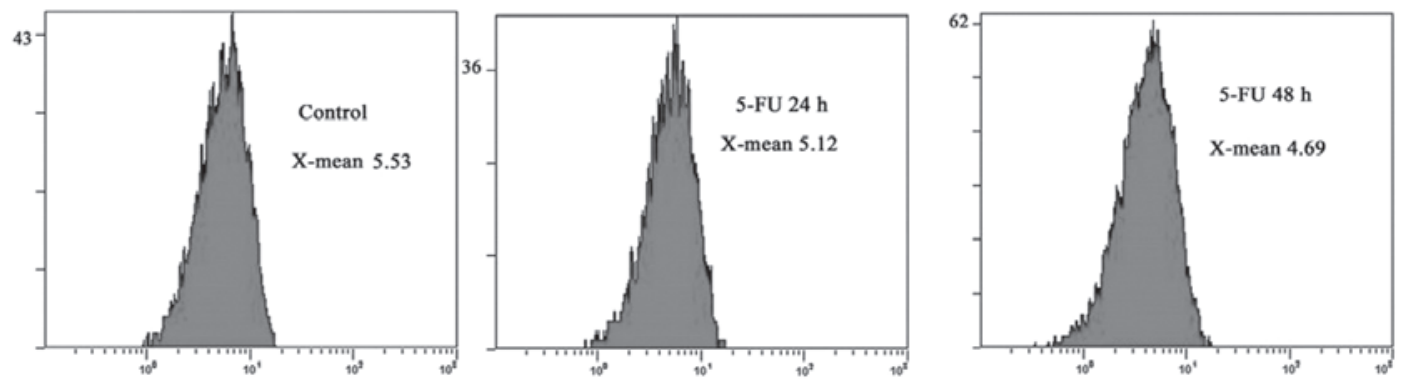

B

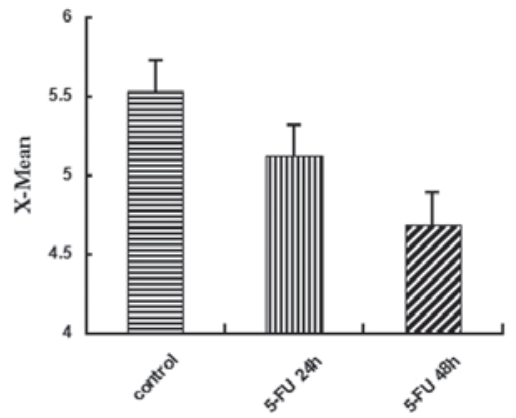

C

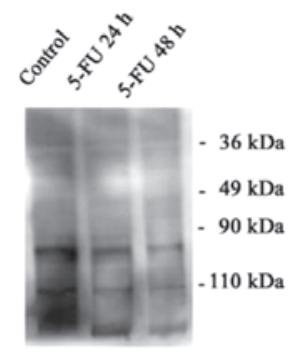

Figure 4. Effect of 5-FU on the levels of polylactosamine expressed in colon cancer cells. (A) The expression of polylactosamine was recognized by LEL staining. The intensity of LEL staining is shown as X-mean. In the untreated cancer cells (control group) and the cells treated with $13 \mu \mathrm{g} / \mathrm{ml} 5$-FU for $24 \mathrm{~h}$ (5-FU $24 \mathrm{~h}$ group) and $48 \mathrm{~h}$ (5-FU $48 \mathrm{~h}$ group), the X-mean was 5.53, 5.12 and 4.69, respectively. (B) The X-mean values of the colorectal cancer cells by flow cytometric analysis at different time points. (C) Analysis of polylactosamine by lectin blot at different time-points. FU, fluorouracil; LEL, lycopersicon esculentum agglutinin lectin.

with $13 \mu \mathrm{g} / \mathrm{ml} 5-\mathrm{FU}$ for $48 \mathrm{~h}$ increased the percentage of apoptotic cells to $9.29 \%$, compared with the control, which contained only $1.05 \%$ apoptotic cells $(\mathrm{P}<0.05)$.

5-FU increases cell cycle arrest. 5-FU is an antimetabolite that acts by specifically blocking cells in the S-phase. As shown in Fig. 3, 5-FU caused a significant increase in the percentage of SW620 cells in S phase, and a decrease in cells in $G_{0} / G_{1}$ and $\mathrm{G}_{2} / \mathrm{M}$ phases following incubation with 5 -FU for $48 \mathrm{~h}$. Compared with the untreated cells, the percentage of cells in S-phase was increased from 22.36 to $54.48 \%(\mathrm{P}<0.05)$. However, in the presence of 5-FU, the percentage of SW620 cells in $\mathrm{G}_{0} / \mathrm{G}_{1}$ phase was decreased from 58.95 to $28.62 \%$, while the percentage of cells in $\mathrm{G}_{2} / \mathrm{M}$ phase was decreased from 18.68 to $16.89 \%(\mathrm{P}<0.05)$.
5-FU decreases polylactosamine levels in colon cancer cells. The plant lectins LEL preferentially recognize glycopeptides containing longer polylactosamine repeats. As shown in Fig. 4A, the treatment of SW620 cells with 5-FU markedly reduced LEL staining, indicating the effectiveness of 5-FU treatment in reducing lactosamine addition to $\mathrm{N}$-glycans $(\mathrm{P}<0.05)$. The intensity of LEL staining is presented as the X-mean-value. As shown in Fig. 4A, treatment of SW620 cells with 5-FU markedly reduced LEL staining, indicating the effectiveness of 5-FU treatment in reducing polylactosamine. In the untreated cancer cells (control group) and the cells treated with $13 \mu \mathrm{g} / \mathrm{ml}$ 5-FU for $24 \mathrm{~h}$ (5-FU 24-h group) or $48 \mathrm{~h}$ (5-FU 48-h group), the $\mathrm{X}$-mean was 5.53, 5.12 and 4.69, respectively. Next, the separated glycoproteins were transferred onto polyvinylidene difluoride 
A

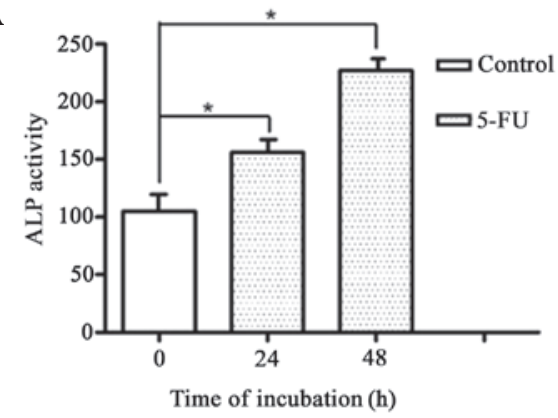

B

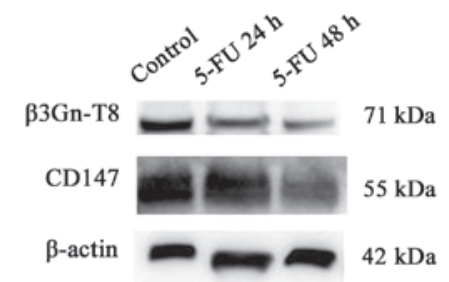

Figure 5. Effect of 5-FU on cell differentiation and the expression of $\beta 3 \mathrm{Gn}-\mathrm{T} 8$ and CD147. (A) Effect of 5-FU on ALP activity after 24 or $48 \mathrm{~h}$ of culture with $13 \mu \mathrm{g} / \mathrm{ml} 5-\mathrm{FU}$ ("P $<0.05$ vs. control). (B) Expression levels of $\beta 3 \mathrm{Gn}-\mathrm{T} 8$ and CD147 protein in different SW620 cells at different time-points. FU, fluorouracil; ALP, alkaline phosphatase; CD147, cluster of differentiation 147; $\beta 3 \mathrm{Gn}-\mathrm{T} 8, \beta 1,3-\mathrm{N}$-acetylglucosaminyltransferase- 8 .

membranes. The data revealed that polylactosamine levels were generally decreased in the glycoproteins in the SW620 cells following 5-FU treatment (Fig. 4C). The lectin blot assay revealed similar results to those of the flow cytometric assay. These data indicated that 5-FU generally altered the polylactosamine structures of the $\mathrm{N}$-glycans among the glycoproteins of SW620 cells. To the best of our knowledge, the present study is one of the first to focus on the changes of polylactosamines in human colon cancer cells affected by 5 -FU.

5-FU increases cell differentiation. The structures of polylactosamines are often characteristic for different cell types and stages of differentiation. ALP has been used to monitor the differentiation effect of certain anticancer compounds. Therefore, in the present study, the ALP activity was observed. Untreated SW620 cells exhibited relatively low ALP activity (Fig. 5A), while in cells treated with $13 \mu \mathrm{g} / \mathrm{ml} 5-\mathrm{FU}$, the activity of ALP reached high levels in a time-dependent manner. There was a significant difference between the control and treated cells $(\mathrm{P}<0.05)$.

Changes in the expression of $\beta 3 G n-T 8$ and CD147 following 5-FU treatment. Western blot analysis revealed that the expression of $\beta 3 \mathrm{Gn}-\mathrm{T} 8$ in the SW620 cells was markedly suppressed by 5 -FU (Fig. 5B). Treatment of SW620 cells with 5-FU also resulted in a marked decrease in CD147 at the protein level in a time-dependent manner (Fig. 5B). These results were consistent with those of the lectin blot analysis in vitro.

\section{Discussion}

Multiple pathways are known to be targeted by 5-FU, and as a consequence, its effect may be modulated by a number of genes and gene products within those pathways. Not all the major targets and pathways affected by 5 -FU are known, which limits the possibilities of predicting the effectiveness of the drug in individual patients. Therefore, understanding the mechanism that contributes to the response of cancer cells to 5-FU is important for determining how to control tumor growth and therapy. The present study has specifically focused on colon cancer, a major malignancy with insufficient treatment options and one of the leading causes of cancer mortality throughout the world. In the present study, the polylactosamine structures of $\mathrm{N}$-glycans in glycoproteins were demonstrated to be generally altered following 5-FU treatment in colon cancer cells, although the data are not conclusive.

As a major anticancer drug for the treatment of colorectal carcinoma, 5-FU has modest clinical activity at standard doses, and in general, dosing is limited by its safety profile. As a result, decisions with regard to the therapeutic dose of 5-FU are challenging for clinicians. In the present study, the $\mathrm{IC}_{50}$-value of 5-FU on colon cancer cells over a 48-h treatment period was determined in vitro using the MTT assay. The obtained $\mathrm{IC}_{50}$-value in regard to a $48-\mathrm{h}$ exposure of SW620 to $13 \mu \mathrm{g} / \mathrm{ml}$ 5-FU was comparable with that previously observed (14). Since the PPC of 5-FU in colon cancer patients is $\sim 10 \mu \mathrm{g} / \mathrm{ml}$, the data of the present study are clinically relevant. However, it was confirmed that treatment with 5-FU was able to induce variable degrees of apoptosis in cultured cells. Apoptosis is a form of cell death defined by a characteristic set of morphological and biochemical changes. The data in the present study, obtained from Hoechst 33258 staining and flow cytometric analysis, indicated that 5-FU administration also resulted in apoptosis in SW620 cells. In addition, pretreatment with 5-FU induced an accumulation of SW620 cells in the S phase of the cell cycle. Observations from the present study have shown that 5-FU has a significant role in the therapy of human colon cancer.

Altered glycosylation is a universal feature of cancer cells, and certain glycan structures are well-known markers for tumor progression (15). It is well known that the expression of $\mathrm{N}$-glycans as constituents of cell surface glycoproteins is essential for the regulation of various processes in tumor cell biology. The amount of tetra-antennary and triantennary N-glycans is often associated with the increased amount of polylactosamine (16). This is in particular due to the $\beta 1,6$ branch of the $\mathrm{N}$-glycans being one of the favored sites for polylactosamine substitutions (17). There are two major roles with regard to the function of polylactosamines. Alterations in polylactosamines of tumor cells are correlated with carcinogenesis, invasion and metastasis (18). Thus, the inhibition of glycan synthesis reduces tumorigenicity. Furthermore, the structures of polylactosamines are often characteristic of different cell types and stages of differentiation (19). Saitoh et al showed that the polylactosamine content was decreased after colon cancer $\mathrm{CaCo}-2$ cells were differentiated and lost their tumorigenicity (9). The results of the present study further revealed that 5-FU specifically affected the expression of polylactosamine, as indicated by lectin blot and flow cytometric assays. In addition, ALP activity was examined as a marker for cellular differentiation in human colon cancer cells (20). Similar to the change of glycans, treatment with 5-FU increased ALP activity in cancer cells in the present study. Thus, it may be hypothesized that microenvironmental changes in the synthesis of glycans greatly affect their synthetic efficiency and also their structures. However, it has been challenging to analyze polylactosamine in a comprehensive and 
quantitative manner, since a very low amount of glycans is available in biological samples.

The polylactosamine of $\mathrm{N}$ - and $\mathrm{O}$-glycans is coordinately synthesizedby thealternateaction of $\beta 1$-4-galactosyltransferases and $\beta 3 \mathrm{Gn}$-Ts (21). In different types of glycoconjugates and cells at various stages of differentiation, the presence of $\beta 3 \mathrm{Gn}-\mathrm{T}$ is also completely different. In comparison to normal tissue, the majority of colorectal cancer tissues that have been examined have been found to have significantly higher levels of the $\beta 3 \mathrm{Gn}-\mathrm{T} 8$ transcript (10). The result of the present study revealed that the expression of $\beta 3 \mathrm{Gn}-\mathrm{T} 8$ in SW620 cells was evidently suppressed by 5-FU. Notably, the potential anticancer activity of 3'-azido-3'-deoxythymidine, which is able to inhibit the synthesis of polylactosamine, is able to be modulated by combining it with 5-FU $(22,23)$. In this manner, the differential expression of $\beta 3 \mathrm{Gn}-\mathrm{T} 8$ in SW620 cells that is responsible for polylactosamine chain elongation may be affected by $5-\mathrm{FU}$ and further studies are required to confirm this.

Furthermore, polylactosamine glycosylation is performed preferentially to select proteins. CD147 is a major carrier of $\beta 1,6$-branched polylactosamine sugars on tumor cells (24). In the present study, the treatment of SW620 cells with 5-FU resulted in a marked decrease of CD147 at the protein level. Traditionally, the biosynthesis of the glycans in glycoproteins is regulated by a number of factors, including i) Expression of associated glycosyltransferases and/or glycosidases, ii) proper locations and iii) the functional machinery of sugar nucleotides (25). The present observations of downregulated CD147 expression lead to the hypothesis that one of the mechanisms underlying the anticancer effect of 5-FU on colon cancer is the suppression of the biosynthesis of polylactosamines. However, it remains to be elucidated whether other genes exist that encode for proteins with this activity.

In conclusion, 5-FU has been shown to exhibit anticancer effects by the induction of apoptosis and cell cycle arrest. 5-FU also decreased polylactosamine in colon cancer cells. In conclusion, the present study indicates that polylactosamine may be a potential target that contributes to the 5-FU response in colon cancer cells. It may thus be a novel drug target candidate for the treatment of colon cancer.

\section{Acknowledgements}

The present study was supported the National Natural Science Foundation of China (nos 30670462 and 31170772), the Master Start-up Foundation of Hubei University of Medicine (nos 2010QDJ20 and 2010QDJ21) and the Research and Innovation Project for College Graduates of Jiangsu Province (CXZZ13_0827).

\section{References}

1. Zhang DQ, Guo Q, Zhu JH and Chen WC: Increase of cyclooxygenase-2 inhibition with celecoxib combined with 5-FU enhances tumor cell apoptosis and antitumor efficacy in a subcutaneous implantation tumor model of human colon cancer. World J Surg Oncol 11: 16, 2013.

2. Kalra AV and Campbell RB: Mucin impedes cytotoxic effect of 5-FU against growth of human pancreatic cancer cells: overcoming cellular barriers for therapeutic gain. Br J Cancer 97: 910-918, 2007.

3. De Graaf TW, Slot SS, Peters GJ and Van Dijk W: Changes in glycosylation of L1210 cells after exposure to various antimetabolites. Eur J Cancer 29A: 1760-1765, 1993.
4. Yang JM, Byrd JC, Siddiki BB, et al: Alterations of O-glycan biosynthesis in human colon cancer tissues. Glycobiology 4: 873-884, 1994.

5. Barrow H, Tam B, Duckworth CA, Rhodes JM and Yu LG: Suppression of core $1 \mathrm{Gal}$-transferase is associated with reduction of TF and reciprocal increase of Tn, sialyl-Tn and Core 3 glycans in human colon cancer cells. PLoS One 8: e59792, 2013.

6. Balog CI, Stavenhagen K, Fung WL, et al: N-glycosylation of colorectal cancer tissues: a liquid chromatography and mass spectrometry-based investigation. Mol Cell Proteomics 11: 571-585, 2012

7. Hahne H, Neubert P, Kuhn K, et al: Carbonyl-reactive tandem mass tags for the proteome-wide quantification of $\mathrm{N}$-linked glycans. Anal Chem 84: 3716-3724, 2012.

8. Togayachi A, Kozono Y,Ishida H, et al: Polylactosamine on glycoproteins influences basal levels of lymphocyte and macrophage activation. Proc Natl Acad Sci USA 104: 15829-15834, 2007.

9. Saitoh O, Wang WC, Lotan R and Fukuda M: Differential glycosylation and cell surface expression of lysosomal membrane glycoproteins in sublines of a human colon cancer exhibiting distinct metastatic potentials. J Biol Chem 267: 5700-5711, 1992.

10. Ishida H, Togayachi A, Sakai T, et al: A novel beta1,3-N-acetylglucosaminyltransferase (beta3Gn-T8), which synthesizes poly-N-acetyllactosamine, is dramatically upregulated in colon cancer. FEBS Lett 579: 71-78, 2005.

11. Zhu S, Chu D, Zhang Y, et al: EMMPRIN/CD147 expression is associated with disease-free survival of patients with colorectal cancer. Med Oncol 30: 369, 2013.

12. Jiang Z, Ge Y, Zhou J, Xu L and Wu SL: Subcellular localization and tumor distribution of human beta3-galactosyltransferase by beta3GalT7 antiserum. Hybridoma (Larchmt) 29: 141-146, 2010.

13. Peng ZH, Xing TH, Qiu GQ and Tang HM: Relationship between Fas/FasL expression and apoptosis of colon adenocarcinoma cell lines. World J Gastroenterol 7: 88-92, 2001.

14. Tong J, Xie G, He J, Li J, Pan F and Liang H: Synergistic antitumor effect of dichloroacetate in combination with 5-fluorouracil in colorectal cancer. J Biomed Biotechnol 2011: 740564, 2011.

15. Remmers N, Anderson JM, Linde EM, et al: Aberrant expression of mucin core proteins and o-linked glycans associated with progression of pancreatic cancer. Clin Cancer Res 19: 1981-1993, 2013.

16. Mitsui Y, Yamada K, Hara S, Kinoshita M, Hayakawa T and Kakehi K: Comparative studies on glycoproteins expressing polylactosamine-type N-glycans in cancer cells. J Pharm Biomed Anal 70: 718-726, 2012.

17. Srinivasan N, Bane SM, Ahire SD, Ingle AD and Kalraiya RD: Poly N-acetyllactosamine substitutions on $\mathrm{N}$ - and not $\mathrm{O}$-oligosaccharides or Thomsen-Friedenreich antigen facilitate lung specific metastasis of melanoma cells via galectin-3. Glycoconj J 26: 445-456, 2009.

18. Nabi IR and Dennis JW: The extent of polylactosamine glycosylation of MDCK LAMP-2 is determined by its Golgi residence time. Glycobiology 8: 947-953, 1998.

19. Seko A and Yamashita K: Activation of beta1,3-N-acetylglucosaminyltransferase-2 (beta3Gn-T2) by beta3Gn-T8. Possible involvement of beta $3 \mathrm{Gn}-\mathrm{T} 8$ in increasing poly- $\mathrm{N}$-acetyllactosamine chains in differentiated HL-60 cells. J Biol Chem 283: 33094-33100, 2008.

20. Lea MA, Ibeh C, Shah N and Moyer MP: Induction of differentiation of colon cancer cells by combined inhibition of kinases and histone deacetylase. Anticancer Res 27: 741-748, 2007.

21. Seko A and Yamashita K: Characterization of a novel galactose beta1,3-N-acetylglucosaminyltransferase (beta3Gn-T8): the complex formation of beta3Gn-T2 and beta3Gn-T8 enhances enzymatic activity. Glycobiology 15: 943-951, 2005.

22. Andreuccetti M, Allegrini G, Antonuzzo A, et al: Azidothymidine in combination with 5-fluorouracil in human colorectal cell lines: in vitro synergistic cytotoxicity and DNA-induced strand-breaks. Eur J Cancer 32A: 1219-1226, 1996.

23. Steet RA, Melancon P and Kuchta RD: 3'-Azidothymidine potently inhibits the biosynthesis of highly branched N-linked oligosaccharides and poly- $\mathrm{N}$-acetyllactosamine chains in cells. J Biol Chem 275: 26812-26820, 2000.

24. Tang W, Chang SB and Hemler ME: Links between CD147 function, glycosylation, and caveolin-1. Mol Biol Cell 15: 4043-4050, 2004.

25. Dube DH and Bertozzi CR: Glycans in cancer and inflammation - potential for therapeutics and diagnostics. Nat Rev Drug Discov 4: 477-488, 2005. 